\title{
Administrative Claims Analysis of Asthma-Related Health Care Utilization for Patients Who Received Inhaled Corticosteroids With Either Montelukast or Salmeterol as Combination Therapy
}

\author{
FELICIA C. ALLEN-RAMEY, PhD; DON BUKSTEIN, MD; ALLAN LUSKIN, MD; \\ SHIVA G. SAJJAN, PhD; and LEONA E. MARKSON, ScD
}

\begin{abstract}
OBJECTIVE: To compare asthma-related health care resource utilization among a matched cohort of asthma patients using inhaled corticosteroids (ICSs) plus either montelukast (MON) or salmeterol (SAL) as combination therapy for asthma, during a time prior to the availability of fixed-dose combinations of ICS/SAL.

METHODS: A retrospective analysis using the PHARMetrics patient-centric claims database was conducted for the period preceding the market introduction of combination fluticasone-SAL in September 2000. Patients had to meet the following criteria for inclusion in the study: they had to be between the ages of 4 and 55 years; they had to have been continuously enrolled for 2 years; they had to have initiated ICS/MON or ICS/SAL therapy between July 1, 1998, and June 30, 1999; and they had to have had either (a) a diagnosis of asthma (based on International Classification of Diseases, Ninth Revision, Clinical Modification (ICD-9-CM) codes of 493.xx) for 2 outpatient visits, 1 or more emergency department (ED) visits, or 1 or more hospitalizations within 1 year or (b) pharmacy claim records that contained a National Drug Code for an antiasthma medication (betaagonist, theophylline, ICS, cromolyn, or leukotriene) 2 or more times within 1 year ICS/MON and ICS/SAL patients were matched 1 to 1 on age and propensity score. Outcomes included asthma-related hopitalizations and ED visits with ICD-9-CM codes of 493.xx, and oral corticosteroid (OCS) fills and short-acting beta-agonist (SABA) fills. Multivariate regression analyses were performed. Subgroup analyses based on sequential or concurrent initiation of combination therapy were also conducted.
\end{abstract}

RESULTS: $A$ total of 1,216 patients were matched (ICS/MON=608; ICS/SAL= 608). Decreased odds of ED visits and/or hospitalizations were observed with ICS/MON (adjusted odds ratio [OR] = 0.58; 95\% confidence interval [CI], 0.350.98 ) versus ICS/SAL. The odds of postindex OCS fills were not different for ICS/MON and ICS/SAL patients (adjusted OR=1.04; 95\% Cl, 0.79-1.38). Postindex pharmacy claims for SABAs were significantly higher among ICS/MON patients versus ICS/SAL patients (adjusted relative risk $[R R]=1.33 ; 95 \% \mathrm{Cl}, 1.17-1.52$ ), and this difference remained regardless of prior use or no prior use of ICSs. In subgroup analyses, mean change in SABA fills varied by how combination therapy was initiated, with sequential addition of asthma controllers leading to a reduction in SABA fills in both groups. For patients with concurrent initiation of combination therapy, the odds of ED visits/hospitalizations were significantly lower in patients initiating ICS/MON (adjusted $\mathrm{OR}=0.25 ; 95 \% \mathrm{Cl}, 0.08-0.79$ ).

CONCLUSION: In this matched cohort, use of ICS/MON compared with ICS/SAL resulted in similar odds of OCS fills, decreased odds of ED visits and asthmarelated hospitalizations, but higher utilization of SABA.

KEYWORDS: Asthma, Montelukast, Salmeterol, Inhaled corticosteroids, Combination therapy, Propensity scoring, Leukotriene

J Manag Care Pharm. 2006;12(4):310-21
$\mathrm{T}$ he National Asthma Education and Prevention Program (NAEPP) Expert Panel advocates a stepwise approach to the treatment of asthma. ${ }^{1}$ Both the 1997 guidelines, which were in effect at the time of this study, and the 2002 revision provide similar recommendations. ${ }^{2}$ For moderate persistent asthma (daily symptoms requiring daily use of an inhaled shortacting beta-agonist [SABA] and exacerbations affecting activity $\geq 2$ times per week and nighttime symptoms $>1$ time per week), NAEPP guidelines recommend daily use of a low-to-medium dose of an inhaled corticosteroid (ICS) plus a long-acting betaagonist (LABA) or, alternatively, a leukotriene receptor antagonist (LRA) for long-term control.

Since the publication of these guidelines, additional evidence from both clinical trials and retrospective studies examining combination therapies has become available. Results of clinical trials examining ICSs plus LRAs versus ICSs plus LABAs reveal both combination therapies to be effective, ${ }^{3}$ but the results from the clinical trials are inconsistent and do not provide a clear advantage for either therapeutic regimen. ${ }^{4-9}$ In a 52-week trial, Bjermer et al. found that $20.1 \%$ of the patients receiving montelukast $(\mathrm{MON})$ and fluticasone had an asthma exacerbation compared with $19.1 \%$ in the group receiving salmeterol (SAL) and fluticasone (relative risk $[\mathrm{RR}]=1.05$ for MON/fluticasone vs. SAL/fluticasone; 95\% confidence interval $[\mathrm{CI}], 0.86-1.29){ }^{8}$

Ilowite et al. conducted a 48-week study of patients with moderate-to-severe persistent asthma symptomatic on inhaled fluticasone (220 mg daily) randomized to the addition of SAL (84 mg/day) or MON (10 mg/day). Of those randomized,

\section{Authors}

FELICIA C. ALLEN-RAMEY, PhD, is senior manager; SHIVA G. SAJJAN, PhD, is manager; and LEONA E. MARKSON, SCD, is executive director, Outcomes Research and Management, Merck \& Co., West Point, Pennsylvania; DON BUKSTEIN, MD, is assistant clinical professor of pediatrics and family practice, and ALLAN LUSKIN, MD, is clinical associate professor of medicine, University of Wisconsin, Madison.

AUTHOR CORRESPONDENCE: Felicia C. Allen-Ramey, PhD, Senior Manager, Outcomes Research and Management, Merck \& Co. Sumneytown Pike, WP39-170, West Point, PA 19486-0004

Tel: (215) 652-7546; Fax: (215) 652-0860; E-mail: felicia_ramey@merck.com Copyright $\odot$ 2006, Academy of Managed Care Pharmacy. All rights reserved. 


\section{Administrative Claims Analysis of Asthma-Related Health Care Utilization for Patients Who Received}

Inhaled Corticosteroids With Either Montelukast or Salmeterol as Combination Therapy

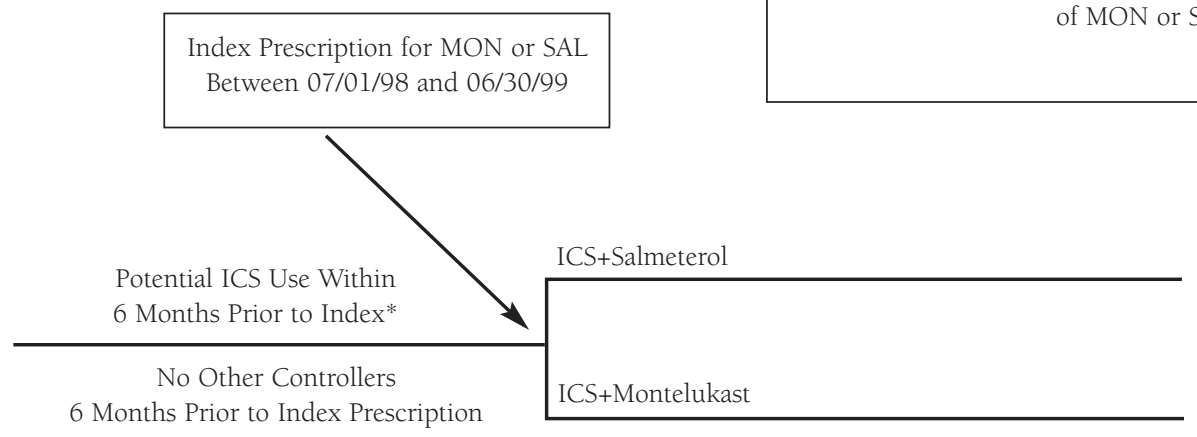

Postindex: ICS Within 60 Days After Addition of MON or SAL; No Other Controllers Within 30 Days After Addition of MON or SAL

\begin{tabular}{|l|l|}
\hline Preindex: 12 Months & Postindex: 12 Months \\
\hline
\end{tabular}

\begin{tabular}{|c|c|c|}
\hline Sample Selection Criteria & $\begin{array}{l}\text { No. of Patients } \\
\text { Dropped }(\%)\end{array}$ & $\begin{array}{l}\text { No. of Patients } \\
\text { Remaining (\%) }\end{array}$ \\
\hline $\begin{array}{l}\text { Diagnosis and drug use: ages } 4-55 \text { years, with an asthma diagnosis (diagnosis code for asthma on a medical } \\
\text { claim or at least } 2 \text { pharmacy claims for asthma medications within a } 365 \text {-day period), a claim for ICS/MON } \\
\text { or ICS/SAL during the index period (07/01/1998-6/30/1999) and no evidence of use of SAL or MON in the } \\
6 \text { months prior to the index date and no other controllers within } 30 \text { days after the index date }\end{array}$ & - & 12,251 \\
\hline Continuous enrollment: 12 months prior to and 12 months following the index date & $3,628(29.6)$ & $8,623(70.4)$ \\
\hline Identify sequential addition: $\geq 1$ pharmacy claim for an ICS within 6 months prior to the index date & $4,327(35.3)$ & $4,296(35.1)$ \\
\hline $\begin{array}{l}\text { No evidence of switching of medications: patients with continued use of an ICS within } 60 \text { days after the index } \\
\text { date }\end{array}$ & $1,010(8.2)$ & $3,286(26.8)$ \\
\hline $\begin{array}{l}\text { Identification of comorbid conditions: patients who do not have a diagnosis of COPD, cystic fibrosis, broncho- } \\
\text { pulmonary dysplasia, or pharmacy claims for ipratropium bromide or ipratropium bromide plus albuterol }\end{array}$ & $115(0.9)$ & $3,171 \dagger(25.9)$ \\
\hline
\end{tabular}

$80.0 \%$ percent of patients in the MON group and $83.3 \%$ of patients in the SAL group remained attack free during the 48 weeks of treatment $(\mathrm{RR}=1.20 ; 95 \% \mathrm{CI}, 0.96-1.49) .{ }^{9}$

Trials of shorter duration showed significant differences between patients using ICS/SAL and ICS/MON. Trials with longer follow-up time (>12 weeks) reported nonsignificant differences. Among patients randomized to SAL/fluticasone combination product compared with those randomized to fluticasone plus MON, Ringdal et al. report significantly greater improvements in forced expiratory volume in 1 second $\left(F E V_{1}\right)$ from baseline (mean treatment difference $=0.11 \mathrm{~L} ; 95 \% \mathrm{CI}, 0.06-0.16$; $P<0.001$ ) and more asthma rescue-free days (odds ratio [OR]
$=1.29 ; 95 \% \mathrm{CI}, 1.02-1.63 ; \mathrm{P}=0.03) .{ }^{6}$ Nelson et al. also note greater improvement in asthma control among patients treated with combination fluticasone plus SAL than those treated with fluticasone plus MON ( $\mathrm{FEV}_{1}$ : + 0.34 L vs. + $0.20 \mathrm{~L}, P<0.001$; days without albuterol use: $+26.3 \%$ vs. $+19.1 \%, P=0.03) .^{5}$ Lastly, in a study of symptomatic patients adding SAL or MON to ICS therapy, Fish et al. also report greater improvement in lung function and asthma symptoms among patients adding SAL (morning peak expiratory flow: $35.0 \mathrm{~L} / \mathrm{min}$ vs. $21.7 \mathrm{~L} / \mathrm{min}$; $P<0.001$; symptom-free days: $24 \%$ vs. $16 \% ; P<0.001)$. Examination of patients beyond a 12 -week period may more closely reflect outcomes seen with chronic use in clinical practice. ${ }^{4}$ 


\section{Administrative Claims Analysis of Asthma-Related Health Care Utilization for Patients Who Received Inhaled Corticosteroids With Either Montelukast or Salmeterol as Combination Therapy}

\section{TABLE 1 Propensity Score Model Using Logistic Regression to Predict the Probability of Receiving Index Drug of ICS Plus Montelukast}

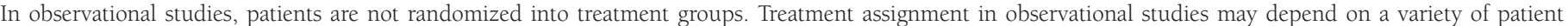

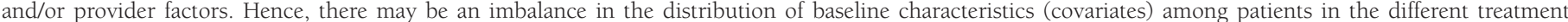

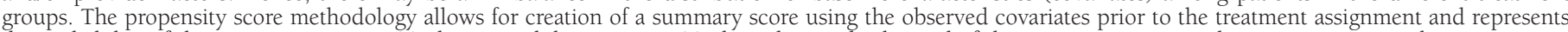

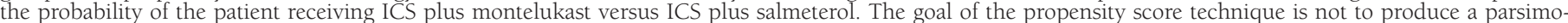

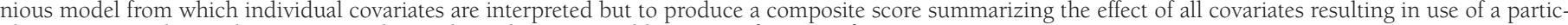
ular treatment. The resulting score can be used to select comparable groups of patients for comparisons.

\begin{tabular}{|c|c|c|c|c|c|c|c|}
\hline Variable* $^{*}$ & OR & $95 \%$ CI & $P$ Value & Variable* $^{*}$ & OR & $95 \%$ CI & $P$ Value \\
\hline Age $\dagger$ & 3.13 & $2.46-3.98$ & $<0.001$ & Prescribing physician\#: allergist & 1.20 & $0.83-1.73$ & 0.34 \\
\hline Male & 1.01 & $0.83-1.23$ & 0.93 & Prescribing physician: pulmonologist & 0.79 & $0.48-1.30$ & 0.36 \\
\hline Preindex pharmacy costs $(\log ) \ddagger$ & 1.30 & $1.08-1.56$ & 0.006 & Prescribing physician: general practitioner & 0.71 & $0.50-1.02$ & 0.06 \\
\hline Proxy for asthma severity§1 & 0.81 & $0.61-1.07$ & 0.14 & Prescribing physician: internist & 1.11 & $0.73-1.69$ & 0.63 \\
\hline Quarter of index prescription\|l: spring & 1.47 & $1.10-1.97$ & 0.009 & Prescribing physician: missing/facility & 1.07 & $0.74-1.55$ & 0.72 \\
\hline Quarter of index prescription: fall & 1.53 & $1.14-2.06$ & 0.004 & Asthma-related hospitalizations preindex & 0.93 & $0.58-1.49$ & 0.77 \\
\hline Quarter of index prescription: winter & 1.62 & $1.19-2.20$ & 0.002 & Asthma-related ED visits preindex & 1.08 & $0.71-1.64$ & 0.71 \\
\hline Serevent Rxs filled preindexII & 0.04 & $0.02-0.08$ & $<0.001$ & Comorbid conditions diagnosed preindex: & & & \\
\hline Cromolyn Rxs filled preindex $\mathbb{1}$ & 1.97 & $1.43-2.71$ & $<0.001$ & Allergic rhinitis & 1.21 & $0.97-1.52$ & 0.10 \\
\hline OCS Rxs filled preindex I & 1.34 & $0.99-1.82$ & 0.06 & Acute upper respiratory conditions & 0.95 & $0.77-1.17$ & 0.63 \\
\hline 1 claim & 1.11 & $0.77-1.60$ & 0.57 & Acute bronchitis & 0.66 & $0.53-0.82$ & $<0.001$ \\
\hline$\geq 2$ claims & & & & Chronic otitis media & 0.96 & $0.73-1.26$ & 0.76 \\
\hline SABA Rxs filled preindex $\mathbb{1}$ & & & & Influenza & 1.10 & $0.71-1.70$ & 0.66 \\
\hline 1-2 claims & 1.01 & $0.83-1.46$ & 0.51 & GERD & 0.77 & $0.53-1.11$ & 0.16 \\
\hline 3-7 claims & 1.14 & $0.81-1.62$ & 0.45 & Nasal polyposis & 1.27 & $0.69-2.36$ & 0.44 \\
\hline$\geq 8$ claims & 1.06 & $0.71-1.57$ & 0.78 & Pneumonia & 0.95 & $0.70-1.27$ & 0.71 \\
\hline ICS Rxs filled preindexII & & & & Rhinorrhea & 1.01 & $0.82-1.23$ & 0.96 \\
\hline 1-2 claims & 1.48 & $1.14-1.93$ & 0.004 & Sinusitis & 1.20 & $0.98-1.47$ & 0.09 \\
\hline$\geq 3$ claims & 2.37 & $1.74-3.22$ & $<0.001$ & Tonsilitis & 1.55 & $0.99-2.41$ & 0.05 \\
\hline Antibiotic Rxs filled preindex II & & & & Pharyngitis & 0.86 & $0.70-1.05$ & 0.14 \\
\hline 1 claim & 0.87 & $0.68-1.12$ & 0.28 & & & & \\
\hline$\geq 2$ claims & 1.03 & $0.79-1.33$ & 0.85 & & & & \\
\hline
\end{tabular}

* Significant interaction terms of preindex outpatient visits and preindex leukotriene modifier use were also included.

+ Binary variable: $\leq 16$ years versus $>16$ years (reference).

\$ Includes antibiotics, cromolyn, ICSs, and SABAs.

$\S$ Four-level proxy for severity based on claims for OCSs and SABAs; binary variable created from the interaction between SABA and OCS prescriptions:

Group 1 (reference, the least severe) versus Groups 2, 3, or 4.**

II Reference category: summer quarter.

II Reference category: zero claims.

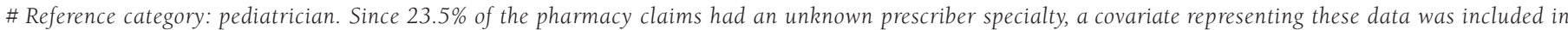
the propensity score model.

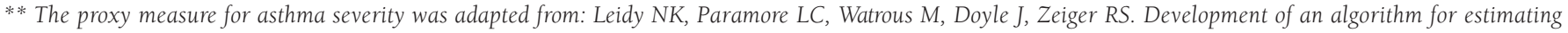
asthma severity from an administrative cost database. Value Health. 1999;2(5):394. In this measure, the most severe group (Group 4) has either (a) $\geq 3$ OCS

fills or (b) 2 OCS fills and $>6$ SABA fills. Group 3 has either (a) 2 OCS fills or (b) $>6$ SABA fills or (c) 1 OCS fill and $\geq 4$ SABA fills. Group 1 has either no

OCS fills and $\leq 1$ SABA fill. All other combinations of SABA and OCS are in Group 2.

$C I=$ confidence interval; $E D=$ emergency department; GERD=gastroesophageal reflux disease; ICS=inhaled corticosteroids; MON = montelukast;

$O C S=$ oral corticosteroid; OR=odds ratio; $R x=$ prescription; $S A B A=$ short-acting beta-agonist; SAL=salmeterol.

The results of retrospective studies of administrative claims data comparing outcomes for patients using these combination regimens have shown similar improvements in emergency department (ED) visits and rescue medication use for ICS/MON and ICS/SAL patients and have yielded varied results on hospitalizations. ${ }^{10-13}$ Using a 1-year predesign/postdesign, Bukstein et al. reviewed claims data for patients aged 5 to 65 years who added SAL or a leukotriene modifier to ICSs. The 


\section{Administrative Claims Analysis of Asthma-Related Health Care Utilization for Patients Who Received Inhaled Corticosteroids With Either Montelukast or Salmeterol as Combination Therapy}

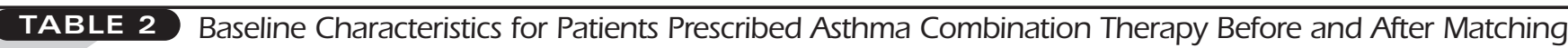

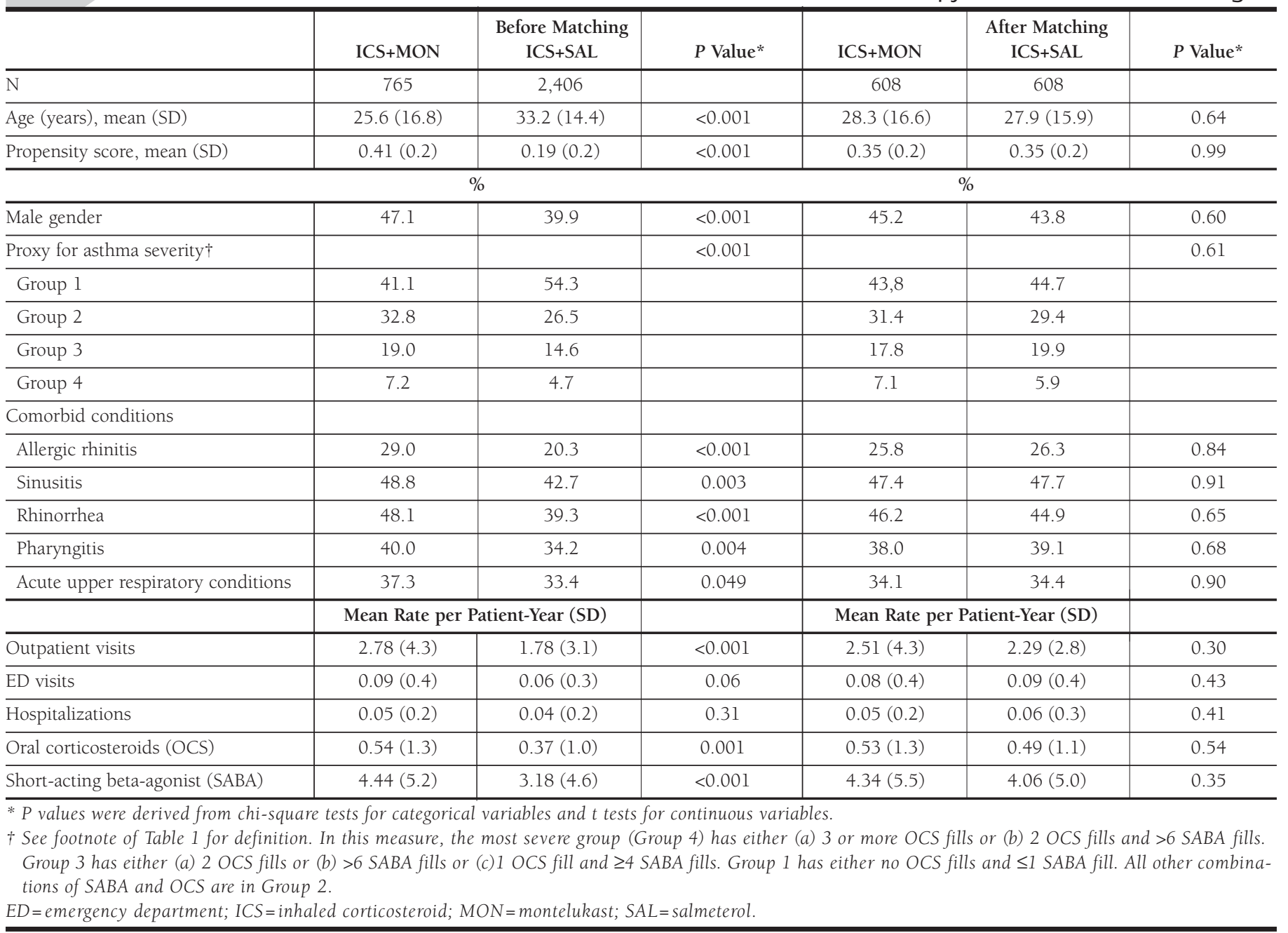

analysis of administrative claims revealed similar decreases in ED visits, urgent care visits, SABA fills, and oral corticosteroid (OCS) fills across the 2 treatment groups. ${ }^{13}$ Stempel et al. also analyzed claims for patients taking an ICS alone prior to adding either MON or SAL. The investigators reported greater odds of an asthma-related hospitalization in patients taking ICS/MON compared with patients taking ICS/SAL (but the ratio was not statistically significant $[\mathrm{OR}=2.5, \mathrm{P}=0.066])$, similar odds of an $\mathrm{ED}$ visit $(\mathrm{OR}=1.28, P=0.372)$, and greater use of a SABA (ICS/MON $=4.45$ vs. $I C S / S A L=3.29, P<0.001$ ), as well as $25 \%$ lower costs in the ICS/SAL group. ${ }^{11}$

A third analysis of administrative claims data performed by O'Connor et al. reported a decline in ED visits and hospitalizations among patients using an ICS plus SAL or an ICS plus an LRA, with a modest increase in SABA use for the leukotriene cohort. ${ }^{12}$ Finally, Wang et al. conducted a cross-sectional exami- nation of medical and pharmacy claims over a 6-month period for patients using combination therapy. While the authors report lower costs for combination therapy of SAL plus fluticasone and ICS plus mast cell stabilizers over other asthma combination regimens, no significant differences in ED visits between patients treated with the fluticasone plus SAL combination (22 \pm 159 per 1,000 ) versus the ICS plus leukotriene combination $(26 \pm 169$ per 1,000) were observed (and no $P$ values were reported for comparisons); similar rates of hospitalizations were also observed (ICS/LRA: $8.4 \pm 91.1$ per 1,000 vs. ICS/SAL: 9.3 \pm 96.1 per 1,000$){ }^{10}$

To assess the relative clinical effectiveness of ICS/MON and ICS/SAL for asthma control, this analysis examined outcomes associated with asthma exacerbations in a clinical practice setting (rather than carefully controlled clinical trials). The objective of the present study was to compare asthma-related 


\section{Administrative Claims Analysis of Asthma-Related Health Care Utilization for Patients Who Received}

Inhaled Corticosteroids With Either Montelukast or Salmeterol as Combination Therapy

\begin{tabular}{|c|c|c|c|}
\hline $\begin{aligned} \text { TABLE 3 } & \text { Baselir } \\
& \text { Accorc }\end{aligned}$ & $\begin{array}{l}\text { Character } \\
\text { g to Prior }\end{array}$ & $\begin{array}{l}\text { of Stuc } \\
\text { of an I }\end{array}$ & ulat \\
\hline & $\begin{array}{l}\text { Prior ICS Use } \\
(\mathrm{N}=815)\end{array}$ & $\begin{array}{l}\text { No Prior } \\
\text { ICS Use } \\
(\mathrm{N}=401)\end{array}$ & $P$ Value* \\
\hline Age (years), mean (SD) & $29.3(16.4)$ & $25.7(15.7)$ & $<0.001$ \\
\hline $\begin{array}{l}\text { Propensity score, mean (SD) } \\
\text { ICS/MON } \\
\text { ICS/SAL }\end{array}$ & $\begin{array}{r}0.40(0.2) \\
0.40(0.18) \\
0.39(0.18)\end{array}$ & $\begin{array}{r}0.24(0.2) \\
0.25(0.15) \\
0.24(0.15)\end{array}$ & $\begin{array}{r}<0.001 \\
- \\
-\end{array}$ \\
\hline Female (\%) & 54.4 & 57.9 & 0.25 \\
\hline $\begin{array}{l}\text { Preindex medication use (SD) } \\
\text { OCS fills } \\
\text { SABA fills } \\
\text { Antibiotic fills }\end{array}$ & $\begin{array}{l}0.59(1.2) \\
5.04(5.5) \\
1.11(1.7)\end{array}$ & $\begin{array}{l}0.35(1.2) \\
2.47(4.1) \\
0.99(1.9)\end{array}$ & $\begin{array}{r}0.002 \\
<0.001 \\
0.30\end{array}$ \\
\hline $\begin{array}{l}\text { Preindex medical visits (SD) } \\
\text { ED visits } \\
\text { Hospitalizations } \\
\text { ED visits and/or hospitalizations }\end{array}$ & $\begin{array}{l}0.09(0.4) \\
0.05(0.3) \\
0.15(0.6)\end{array}$ & $\begin{array}{l}0.06(0.3) \\
0.05(0.2) \\
0.12(0.4) \\
\end{array}$ & $\begin{array}{l}0.16 \\
0.91 \\
0.27 \\
\end{array}$ \\
\hline $\begin{array}{l}\text { Comorbid conditions (\%) } \\
\text { Sinusitis } \\
\text { Allergic rhinitis } \\
\text { Tonsillitis } \\
\text { Rhinorrhea } \\
\text { Acute URI } \\
\text { Conjunctivitis } \\
\text { Chronic otitis media } \\
\text { Nasal polyposis }\end{array}$ & $\begin{array}{r}47.0 \\
26.6 \\
4.7 \\
49.1 \\
34.5 \\
4.1 \\
17.4 \\
2.5\end{array}$ & $\begin{array}{r}48.6 \\
24.9 \\
5.7 \\
38.4 \\
33.7 \\
2.5 \\
14.2 \\
2.2\end{array}$ & $\begin{array}{r}0.59 \\
0.53 \\
0.42 \\
<0.001 \\
0.78 \\
0.17 \\
0.16 \\
0.82\end{array}$ \\
\hline $\begin{array}{l}\text { *P values were derived from } \\
t \text { tests for continuous variab } \\
E D=\text { emergency department; } I \\
M O N=\text { montelukast; OCS =or } \\
\text { beta-agonist; SAL= salmeterol; }\end{array}$ & $\begin{array}{l}\text { square tests } \\
=\text { inhaled cor } \\
\text { corticosteroid } \\
\text { RI= upper res }\end{array}$ & $\begin{array}{l}\text { tegorical vo } \\
\text { eroids; } \\
\text { A= short-a } \\
\text { ry infectio }\end{array}$ & and \\
\hline
\end{tabular}

resource utilization measures (as proxies for asthma control) among a matched cohort of patients using ICS/MON or ICS/SAL. Specifically, ED visits and hospitalizations are analyzed as markers of significant health care utilization for asthma; use of OCSs and SABAs indicate an increase in symptoms. Several studies have documented the association between increasing oral steroid use and/or beta-agonist use with increasing risk of asthma exacerbations. ${ }^{14-16}$ Exacerbations are associated with morbidity, potential mortality, work loss, and decreased quality of life and seem more clinically relevant to payers and patients than other previously used "surrogates" for asthma control. This study has a unique strength through its use of propensity score methodology to obtain comparable groups of patients initiating ICS/MON or ICS/SAL based on patient and provider characteristics that may have influenced treatment selection.

\section{Methods}

\section{Data Source/Study Population}

The PHARMetrics patient-centric database was used as the data source for this analysis. At the time of this analysis, the database contained enrollment data and medical, facility, and pharmacy claims for approximately 17 million privately insured members enrolled in U.S. health plans. Enrolled members are geographically dispersed across the United States, with enrollment in plans in 35 states.

Inpatient, outpatient, and pharmacy claims were included in the dataset, which covered the years 1997 to 2000. To be considered for the analysis, patients had to meet the following criteria: they had to be between the ages of 4 and 55 years; they had to have received a diagnosis of asthma (based on International Classification of Diseases, Ninth Revision, Clinical Modification [ICD-9-CM] codes of 493.xx) at 2 outpatient visits, 1 or more ED visits, or during 1 or more hospitalizations within 1 year, or they had to have pharmacy claim records that contained a National Drug Code for an antiasthma medication (a beta-agonist, theophylline, an ICS, cromolyn, or a leukotriene) 2 or more times within 1 year; and they had to be continuously enrolled for 2 years. Patients were excluded if they had a medical claim with a diagnosis of chronic obstructive pulmonary disease, chronic bronchitis, cystic fibrosis, or bronchopulmonary dysplasia, or if they had pharmacy claims for ipratropium bromide (Atrovent) or ipratropium bromide and albuterol (Combivent).

\section{Study Design}

Among patients identified with asthma, those initiating use of combination therapy were examined for changes in asthmarelated resource utilization. Use of combination therapy was defined as use of an ICS only in the 6 months preceding the addition of a second asthma therapy (SAL or MON) or initiation of an ICS and SAL or MON on the same day, between July 1 , 1998, and June 30, 1999 (index event). Patients had to be continuously enrolled in a health plan with pharmacy benefits for the 12-month period prior to the index prescription (referred to as the preindex period) and for 12 months following the index prescription (referred to as the postindex period) (Figure 1). Patients were excluded if their pharmacy records indicated use of an asthma controller other than an ICS in the 6 months preceding the index event or use of a third asthma controller within 30 days after the addition of MON or SAL. Continued use of both medications was confirmed by identification of another claim for an ICS within 60 days following the addition of MON or SAL.

\section{Propensity Score Analysis}

The propensity score methodology ${ }^{17}$ was used to obtain comparable groups of patients treated with ICS/MON and ICS/SAL based on patient and provider characteristics that may influence treatment selection. The propensity score is the probability of receiving MON versus SAL treatment concomitant with ICS for a given patient. For each patient, the propensity 


\section{Administrative Claims Analysis of Asthma-Related Health Care Utilization for Patients Who Received Inhaled Corticosteroids With Either Montelukast or Salmeterol as Combination Therapy}

\begin{tabular}{|c|c|c|c|c|c|c|c|}
\hline & \multicolumn{3}{|c|}{$\begin{array}{c}\text { ICS/MON } \\
(\mathrm{N}=608) \\
\text { Mean Rate Per Patient-Year (SD) }\end{array}$} & \multicolumn{3}{|c|}{$\begin{array}{c}\text { ICS/SAL } \\
(\mathrm{N}=608) \\
\text { Mean Rate Per Patient-Year (SD) }\end{array}$} & \multirow[b]{2}{*}{$P$ Value } \\
\hline & Preindex & Postindex & Change & Preindex & Postindex & Change & \\
\hline ABA fills & $4.34(5.5)$ & $4.36(5.9)$ & $0.02(4.9)$ & $4.06(5.0)$ & $3.16(4.1)$ & $-0.90(4.1)$ & $<0.001$ \\
\hline CS fills & $0.53(1.3)$ & $0.47(1.2)$ & $-0.06(1.2)$ & $0.49(1.1)$ & $0.42(1.1)$ & $-0.06(1.2)$ & 0.96 \\
\hline Iospitalizations & $0.05(0.2)$ & $0.03(0.2)$ & $-0.02(0.3)$ & $0.06(0.3)$ & $0.04(0.3)$ & $-0.02(0.3)$ & 0.86 \\
\hline
\end{tabular}

* $P$ value represents test of difference in the change for ICS/MON patients versus ICS/SAL patients using bootstrap method with 50,000 iterations. $E D=$ emergency department; ICS=inhaled corticosteroid; $M O N=$ montelukast; OCS=oral corticosteroid; SABA=short-acting beta-agonist; SAL=salmeterol.

score was estimated using a logistic regression model. The variables included in the propensity score model were age, sex, provider specialty of the physician writing the index prescription, season in which combination therapy was prescribed, asthma health care resource use in the year prior to the index prescription (including prior outpatient visits, prior hospitalizations, prior ED visits, prior acute/rescue medication use, and prior antibiotic use), concomitant respiratory conditions, direct pharmacy costs, proxy for asthma severity (see footnote in Table 1), and significant interaction terms determined through forward selection procedure. The result of the propensity model was a single score between 0 and 1 for each patient that summarized the patient's baseline characteristics. The derived propensity score and age groups (4-14 years and $15-55$ years) were used to match patients 1 to 1 across treatment groups (using the Greedy matching technique). ${ }^{18}$ The results of the propensity score model are presented in Table 1; since $23.5 \%$ of the pharmacy claims had an unknown prescriber specialty, a covariate representing these data were included in the propensity score model.

\section{Outcomes}

Asthma-related health resource utilization outcomes included hospitalizations, ED visits, and prescription fills for OCSs and SABAs. The mean change in rates per patient-year from the preindex period to the postindex period was determined for each outcome. Tests of difference in mean change across treatment groups were performed using bootstrap methods with 50,000 iterations. The bootstrapping method was applied because of the skewed distribution of the outcome variables. ${ }^{19}$ Logistic regression models were used to obtain the adjusted odds of postindex ED visits and hospitalizations and postindex fills for OCS. ED visits and hospitalizations were combined into a single composite measure because of the low number of events. Poisson regression was used to obtain an adjusted RR for SABA fills because of the distribution of the number of SABA claims. Model covariates included treatment regimen, gender, age, preindex comorbid conditions, preindex medication use (antibiotics, SABA, LABA, OCS), and preindex resource use.

Additional exploratory analyses were performed to more fully understand the population being examined. Asthma-related outcomes were examined separately for patients using an ICS in the preindex period and adding MON or SAL versus those initiating combination therapy on the same day. A descriptive analysis of baseline (preindex) characteristics for patients who experienced an ED visit and/or hospitalization following the initiation of combination therapy was also conducted. Lastly, because symptoms associated with asthma overlap with symptoms for which antibiotics are often prescribed (i.e., chronic productive cough), change in the number of prescriptions filled for antibiotics during the study period was analyzed.

\section{Results}

\section{Patient Characteristics}

Of 12,251 asthma patients identified in the PHARMetrics database with combination therapy, a total of 3,171 met the inclusion criteria (ICS/MON: $\mathrm{N}=765$; ICS/SAL: $\mathrm{N}=2,406$ ). The patient selection process is presented in Figure 1. Before propensity score matching, the treatment groups differed on a number of baseline characteristics. On average, patients in the ICS/MON cohort were younger (mean age: 25.6 years) versus ICS/SAL (mean age: 33.2 years), had more males (47.1\% ICS/MON vs. $39.9 \%$ ICS/SAL), and had a significantly greater number of outpatient and ED visits per year. In addition, the MON cohort required more rescue medication (in the form of OCSs and/or SABAs) prior to initiating combination therapy and experienced more comorbid respiratory conditions (such as sinusitis, rhinorrhea, pharyngitis, allergic rhinitis, and acute upper respiratory conditions). After being matched on propensity score and age, each treatment group contained 608 patients with similar baseline characteristics, as confirmed by statistical tests. Baseline characteristics of the study population before and after matching are presented in Table 2.

Within the study cohort, 815 patients used an ICS in the 6 months prior to adding MON $(\mathrm{N}=401)$ or SAL $(\mathrm{N}=414)$, and 


\section{Administrative Claims Analysis of Asthma-Related Health Care Utilization for Patients Who Received Inhaled Corticosteroids With Either Montelukast or Salmeterol as Combination Therapy}

\section{FIGURE 2 Results of Multivariate Regression Analyses for Patients Initiating Asthma Combination Therapy $(N=1,216)$}

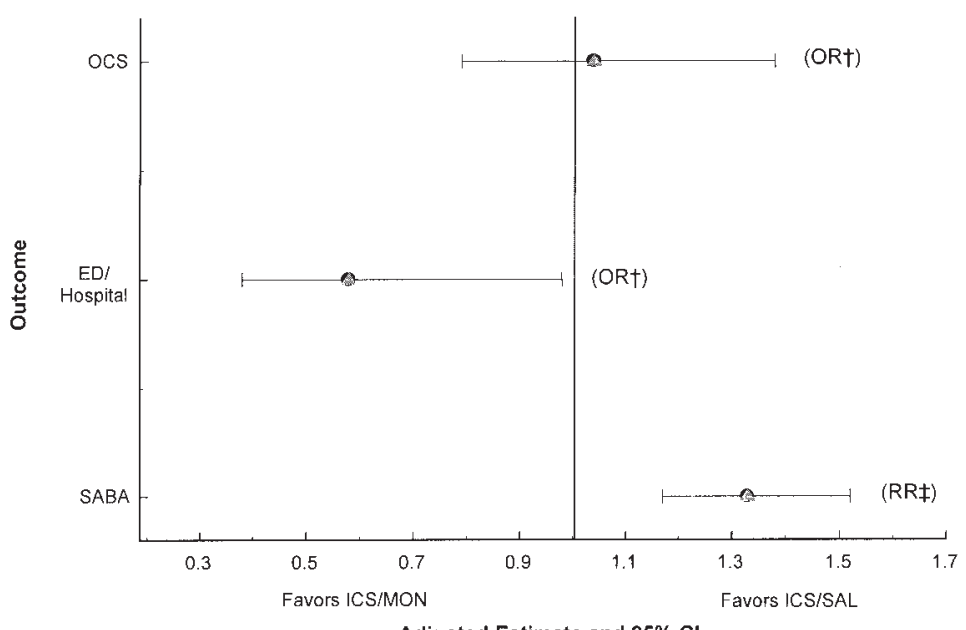

Adjusted Estimate and $95 \% \mathrm{Cl}$

\begin{tabular}{|c|c|c|c|c|}
\hline Model and Covariates* & Coefficient & Adjusted OR $\dagger$ & $95 \% \mathrm{CI}$ & $P$ Value \\
\hline \multicolumn{5}{|l|}{ Postindex OCS fills } \\
\hline ICS/MON treatment & \multirow[t]{2}{*}{0.04} & 1.04 & \multirow[t]{2}{*}{$(0.79,1.38)$} & \multirow[t]{2}{*}{0.76} \\
\hline ICS/SAL treatment & & 1.0 & & \\
\hline Influenza & 0.68 & 1.98 & $(1.12,3.52)$ & 0.02 \\
\hline \multicolumn{5}{|l|}{ Prior OCS fills (ref.: $\geq 2$ claims) } \\
\hline 0 claims & -1.04 & 0.17 & $(0.11,0.26)$ & $<0.001$ \\
\hline 1 claim & 0.32 & 0.67 & $(0.43,1.05)$ & 0.01 \\
\hline \multicolumn{5}{|l|}{ Postindex ED/hospital } \\
\hline ICS/MON treatment & \multirow[t]{2}{*}{-0.54} & 0.58 & \multirow[t]{2}{*}{$(0.35,0.98)$} & \multirow[t]{2}{*}{0.04} \\
\hline ICS/SAL treatment & & 1.0 & & \\
\hline Prior ED/hospital & 0.79 & 2.20 & $(1.14,4.26)$ & 0.02 \\
\hline \multirow[t]{2}{*}{ Chronic otitis media } & 0.61 & 1.83 & $(1.01,3.34)$ & 0.05 \\
\hline & Coefficient & Adjusted RR $¥$ & $95 \% \mathrm{CI}$ & $P$ Value \\
\hline \multicolumn{5}{|l|}{ Postindex SABA fills } \\
\hline ICS/MON treatment & \multirow[t]{2}{*}{0.29} & 1.33 & \multirow[t]{2}{*}{$(1.17,1.52)$} & \multirow[t]{2}{*}{$<0.001$} \\
\hline ICS/SAL treatment & & 1.0 & & \\
\hline \multicolumn{5}{|l|}{ Prior SABA fills (ref.: $\geq 8$ claims) } \\
\hline 0 claims & -1.61 & 0.20 & $(0.16,0.25)$ & $<0.001$ \\
\hline 1-2 claims & -1.56 & 0.21 & $(0.17,0.26)$ & $<0.001$ \\
\hline 3-7 claims & -0.88 & 0.42 & $(0.36,0.49)$ & $<0.001$ \\
\hline \multicolumn{5}{|c|}{$\begin{array}{l}\text { * Only statistically significant variables for each model are shown. Additional covariates for each } \\
\text { model included treatment group, gender, age, preindex comorbid conditions, preindex medication } \\
\text { use (antibiotics, SABA, LABA, OCS). } \\
\dagger \text { Odds ratio }(O R) \text { was estimated from logistic regression model. } \\
\text { † Relative risk (RR) was estimated from Poisson regression model. } \\
C I=\text { confidence interval; ED=emergency department; ICS=inhaled corticosteroid; } \\
\text { LABA=long-acting beta-agonist; MON= montelukast; OCS=oral corticosteroid; OR=odds ratio; } \\
\text { ref. = reference; RR= relative risk; SABA= short-acting beta-agonist; } S A L=\text { salmeterol. }\end{array}$} \\
\hline
\end{tabular}

401 patients initiated combination therapy on the same day $(\mathrm{MON}=207 ; \mathrm{SAL}=194)$. (Table 3). Compared with those without prior ICS use, patients with prior ICS use had a significantly greater number of pharmacy claims in the preindex period for OCS (0.59 vs. 0.35 claims, $P=0.002)$ and $S A B A$ (5.04 vs. 2.47 claims, $P<0.001$ ). Examination of the mean (SD) propensity score among patients with prior ICS use (SAL=0.39 [0.18], $\mathrm{MON}=0.40$ [0.18]) and those initiating combination therapy on the same day $(\mathrm{SAL}=0.24$ $[0.15], \mathrm{MON}=0.25[0.15])$ indicated that patients were adequately matched.

\section{Change in Asthma-Related Resource Utilization}

An analysis of the mean change in annual asthma-related utilization rates was conducted for patients from the preindex to the postindex period for each cohort (Table 4). Hospitalizations declined by the same magnitude in both the ICS/MON group (mean change: -0.02 claims $[S D=0.3]$ ) and the ICS/SAL group (mean change: -0.02 claims $[S D=0.3]$ ) from preindex to postindex period. Likewise, the mean number of $\mathrm{ED}$ visits declined by 0.04 claims $(\mathrm{SD}=0.4)$ and 0.03 claims $(S D=0.5)$ for the ICS/MON and ICS/SAL groups $(P=0.46)$, respectively. Prescriptions for OCSs also declined in nearly identical fashion for those patients using ICS/MON, (mean change: -0.06 claims [SD $=1.2]$ ) as compared with ICS/SAL patients (mean change: -0.06 claims $[S D=1.2]$ ).

Mean change in SABA fills varied by how controller therapy was initiated. For the total population, SABA fills were essentially unchanged for patients using ICS/MON but decreased for ICS/SAL patients (mean change: 0.02 claims $[S D=4.9]$ for ICS/MON vs. -0.90 claims $[S D=4.1]$ for ICS/SAL; $P<0.001)$. Among patients with prior ICS use, SABA fills declined for both the ICS/MON (mean change: -0.40 claims $[\mathrm{SD}=3.7]$ ) and the ICS/SAL groups (mean change: -1.34 claims $[S D=4.3])$; this difference in change was significant $(P=0.001)$. In contrast, patients starting combination therapy on the same day had small increases in SABA fills in both the ICS/SAL (mean change: 0.04 claims $[S D=3.4]$ ) and the 


\section{Administrative Claims Analysis of Asthma-Related Health Care Utilization for Patients Who Received Inhaled Corticosteroids With Either Montelukast or Salmeterol as Combination Therapy}

ICS/MON groups (mean change: 0.85 claims $[S D=6.5])$; this difference was not significant $(P=0.12)$. These data are not shown. Regardless of history of ICS use, lower rates of ED visits, Hospitalizations, and OCS fills were observed for both the ICS/MON and ICS/SAL groups in the postindex period compared with the preindex period.

A total of 62 ED visits and 39 hospitalizations occurred in the postindex period, experienced by 74 patients. Compared with those without a postindex ED visit and/or hospitalization, patients with a postindex ED visit and/or hospitalization had a significantly greater number of pharmacy claims for OCS (0.93 vs. 0.48 claims, $P=0.02$ ) and SABA (7.02 vs. 4.01 claims, $P<0.01$ ) in the preindex period. Patients with an ED visit/hospitalization in the postindex period had a significantly greater number of ED visits ( 0.53 vs. $0.06, P<0.01)$ and/or hospitalizations ( 0.19 vs. $0.04, P=0.01)$ in the preindex period compared with those who did not have an ED visit/hospitalization after initiating combination therapy.

While studies of patients using a single controller therapy have noted significantly less antibiotic use for MON patients, ${ }^{20-21}$ no difference in the mean change in antibiotic prescriptions was observed in this study for the ICS/MON (-0.09 claims) vs. ICS/SAL (-0.08 claims).

\section{Multivariate Regression Analyses}

Logistic regression models of resource use in the postindex period were constructed. For modeling purposes, ED visits and hospitalizations were combined into a single outcome variable indicating the occurrence of an ED visit and/or hospitalization. Results of the models revealed significantly decreased odds of ED visits and/or hospitalizations with ICS/MON (adjusted OR: 0.58; 95\% CI, $0.35-0.98 ; P=0.04$ ) versus ICS/SAL. There were similar odds of postindex use of OCSs for patients using ICS/MON (OR 1.04; 95\% CI, 0.79-1.38; $P=0.76$ ) versus ICS/SAL. For the total population, SABA fills were significantly greater among patients who took ICS/MON versus ICS/SAL (adjusted RR: 1.33 ; 95\% CI, 1.17-1.52; $P<0.001)$. These data are summarized in Figure 2.

\section{FIGURE 3 Results of Multivariate Analyses of Asthma-Related Outcomes for Patients Without a History of Prior ICS Use $(N=401)$}

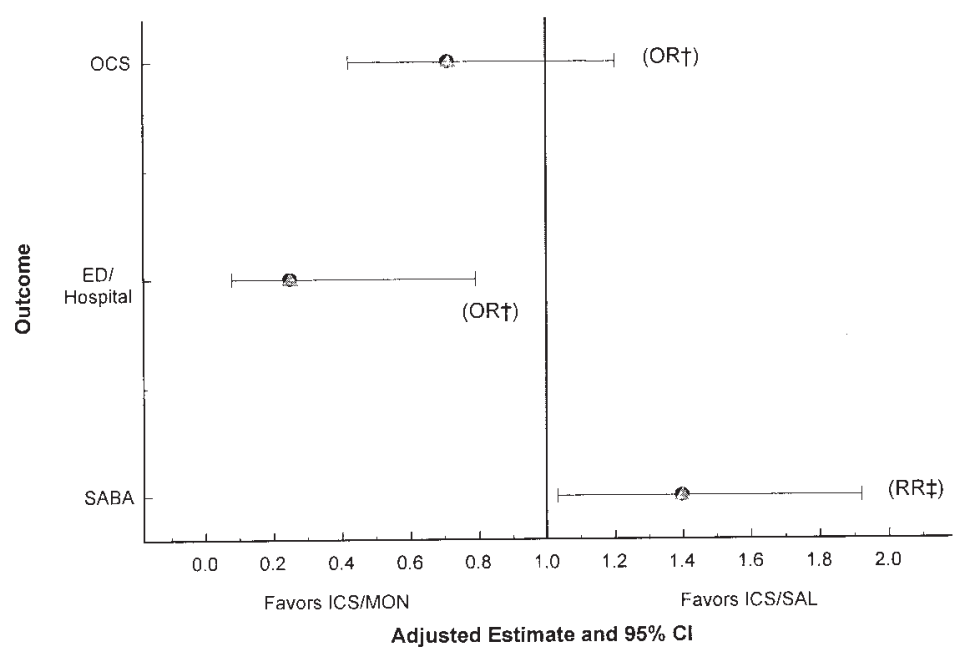

\begin{tabular}{|c|c|c|c|c|}
\hline Model and Covariates* & Coefficient & Adjusted OR $\dagger$ & $95 \% \mathrm{CI}$ & $P$ Value \\
\hline \multicolumn{5}{|l|}{ Postindex OCS fills } \\
\hline ICS/MON treatment & \multirow[t]{2}{*}{-0.34} & 0.71 & \multirow[t]{2}{*}{$0.42-1.20$} & \multirow[t]{2}{*}{0.20} \\
\hline ICS/SAL treatment & & 1.0 & & \\
\hline Age at index & 0.02 & 1.02 & $1.00-1.04$ & 0.04 \\
\hline \multicolumn{5}{|l|}{ Prior OCS fills (ref.: 0 claims) } \\
\hline 1 claim & 1.06 & 2.89 & $1.47-5.70$ & 0.002 \\
\hline$\geq 2$ claims & 2.33 & 10.24 & $4.03-26.03$ & $<0.001$ \\
\hline \multicolumn{5}{|l|}{$\overline{\text { Postindex ED/hospital }}$} \\
\hline ICS/MON treatment & \multirow[t]{2}{*}{-1.39} & 0.25 & \multirow[t]{2}{*}{$0.08-0.79$} & \multirow[t]{2}{*}{0.02} \\
\hline ICS/SAL treatment & & 1.0 & & \\
\hline Prior ED/hospital & 1.26 & 3.54 & $1.01-12.47$ & 0.05 \\
\hline \multicolumn{5}{|l|}{ Prior OCS fills (ref.: 0 claims) } \\
\hline 1 claim & 1.21 & 3.36 & $1.01-11.18$ & 0.05 \\
\hline \multirow[t]{2}{*}{$\geq 2$ claims } & 1.90 & 6.68 & $1.84-24.25$ & 0.004 \\
\hline & Coefficient & Adjusted RR $¥$ & $95 \% \mathrm{CI}$ & $P$ value \\
\hline \multicolumn{5}{|l|}{ Postindex SABA fills } \\
\hline ICS/MON treatment & 0.34 & 1.40 & $1.03-1.92$ & 0.03 \\
\hline ICS/SAL treatment & & 1.0 & & \\
\hline \multicolumn{5}{|l|}{ Prior SABA fills (ref.: $\geq 8$ claims) } \\
\hline 0 claims & -1.42 & 0.24 & $0.16-0.37$ & $<0.001$ \\
\hline 1-2 claims & -1.72 & 0.18 & $0.11-0.29$ & $<0.001$ \\
\hline 3-7 claims & -0.96 & 0.38 & $0.25-0.60$ & $<0.001$ \\
\hline \multicolumn{5}{|c|}{ 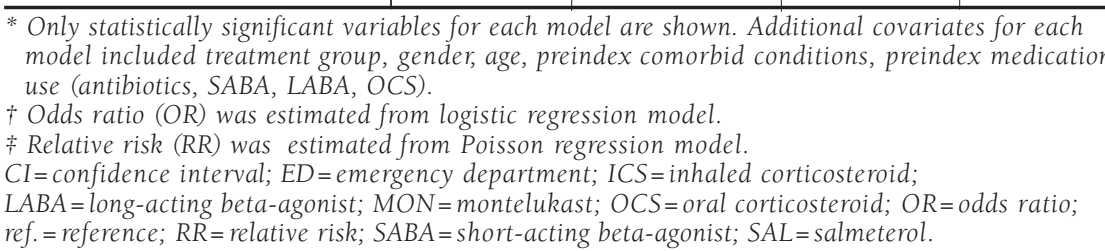 } \\
\hline
\end{tabular}




\section{Administrative Claims Analysis of Asthma-Related Health Care Utilization for Patients Who Received Inhaled Corticosteroids With Either Montelukast or Salmeterol as Combination Therapy}

\section{FIGURE 4 Results of Multivariate Analyses of Asthma-Related Outcomes for Patient With a History of Prior ICS Use (N=815)}

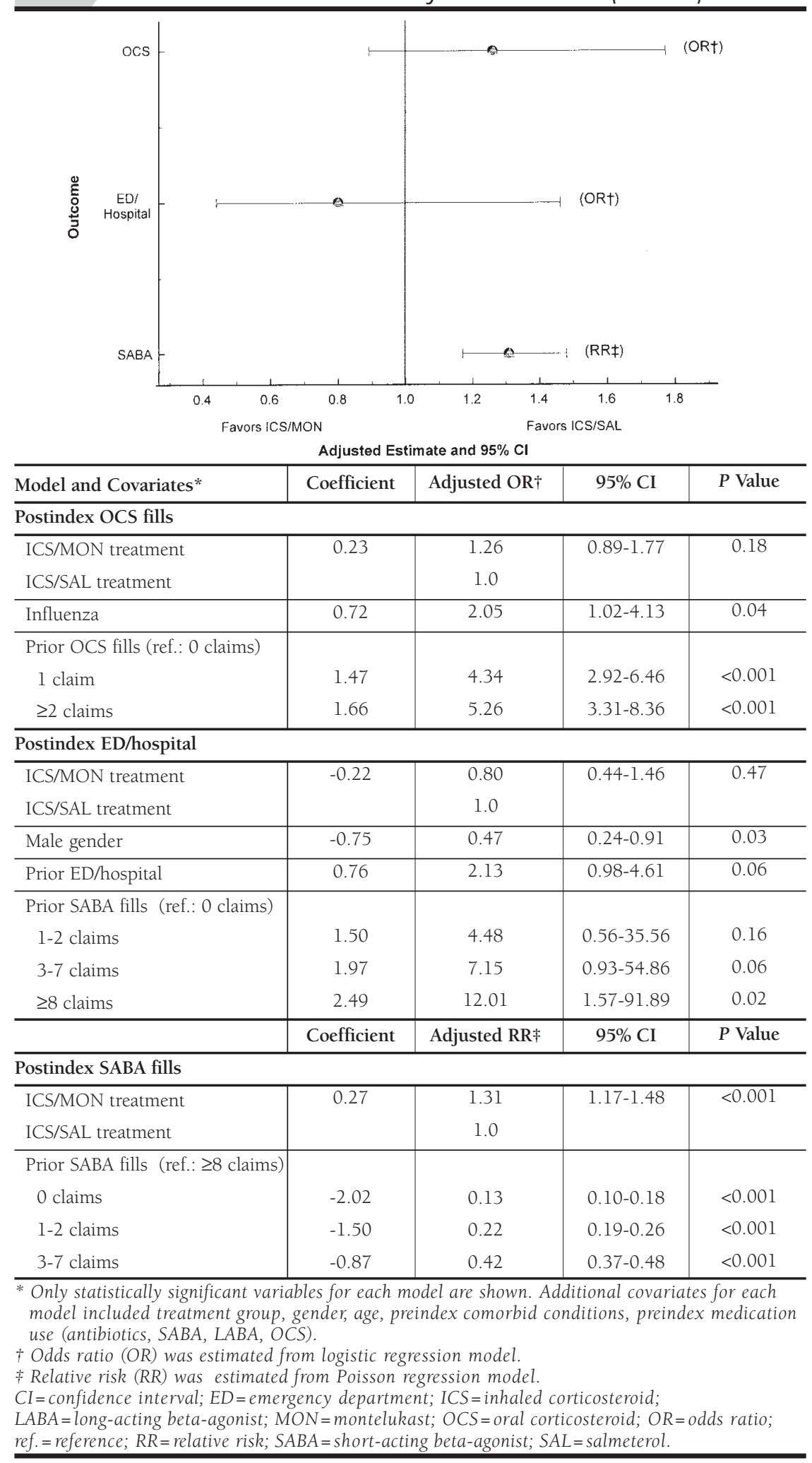

In general, models examining patient outcomes by history of prior ICS use agreed with those of the total population. For patients initiating combination therapy on the same day (Figure 3), ICS/MON use resulted in significantly lower odds of postindex ED visits/hospitalizations $(\mathrm{OR}=$ $0.25 ; 95 \% \mathrm{CI}, 0.08-0.79)$ and greater risk of SABA fills ( $\mathrm{RR}=1.40 ; 95 \% \mathrm{CI}, 1.03-1.92)$; no difference in OCS fills by treatment was observed. For patients adding MON or SAL to ICS (Figure 4), there was no difference in postindex ED visits/hospitalizations or OCS fills across treatment groups; greater risk of SABA fills for ICS/MON patients was observed (RR $=1.3 ; 95 \% \mathrm{CI}, 1.17-1.48)$ as compared with ICS/SAL patients.

In summary, treatment with ICS/SAL was associated with significantly fewer claims for SABA for the total population and for subgroups analyzed by history of ICS use. Patients initiating ICS/MON experienced significantly fewer claims for ED visits/ hospitalizations as seen in the total population and among patients with concurrent initiation of controller therapy. These results were observed in both bivariate and multivariate analyses (Table 5).

\section{Discussion}

This retrospective claims-based analysis compared asthma-related health care resource utilization among a matched patient cohort initiating use of either ICS plus MON or ICS plus SAL as combination therapy for asthma. Multivariate regression analyses of the total population revealed significantly decreased odds of ED visits and/or hospitalizations and no significant difference in OCS fills among users of ICSs and MON compared with users of ICSs and SAL.

The need for rescue medication in the form of a SABA has often been used as a measure of asthma control and was therefore included in this analysis. Regression analyses of the matched cohort indicated a significantly greater decrease in SABA for patients on ICS/SAL - a decrease of 1 canister per patient-year. Analyses of change in SABA varied according to when combination therapy was initiated (sequentially vs. concurrently) and may reflect the patients' 


\section{Administrative Claims Analysis of Asthma-Related Health Care Utilization for Patients Who Received Inhaled Corticosteroids With Either Montelukast or Salmeterol as Combination Therapy}

\section{TABLE 5 Summary of Results of Primary Outcomes Measures for the Overall Study Population}

and Subgroups Using Different Analytic (Bivariate and Multivariate) Methods

\begin{tabular}{|c|c|c|c|c|c|c|}
\hline & \multicolumn{2}{|c|}{$\begin{array}{l}\text { Total Population } \\
\quad(\mathrm{N}=1,216)\end{array}$} & \multicolumn{2}{|c|}{$\begin{array}{l}\text { Prior ICS Use } \\
\quad(\mathrm{N}=815)\end{array}$} & \multicolumn{2}{|c|}{$\begin{array}{l}\text { No Prior ICS Use } \\
\quad(\mathrm{N}=401)\end{array}$} \\
\hline \multicolumn{7}{|c|}{ Bivariate analyses of postindex characteristics* } \\
\hline & $\begin{array}{l}\text { ICS/MON } \\
(\mathrm{N}=608)\end{array}$ & $\begin{array}{l}\text { ICS/SAL } \\
(\mathrm{N}=608)\end{array}$ & $\begin{array}{r}\text { ICS/MON } \\
(\mathrm{N}=401)\end{array}$ & $\begin{array}{l}\text { ICS/SAL } \\
(\mathrm{N}=414)\end{array}$ & $\begin{array}{l}\text { ICS/MON } \\
(\mathrm{N}=207)\end{array}$ & $\begin{array}{l}\text { ICS/SAL } \\
(\mathrm{N}=194)\end{array}$ \\
\hline$\overline{\mathrm{SABA}} *$ & $4.36(5.88)$ & $3.16(4.08)$ & $4.78(5.42)$ & $3.57(4.32)$ & $3.53(6.60)$ & $2.28(3.35)$ \\
\hline OCS & $0.47(1.22)$ & $0.42(1.11)$ & $0.56(1.37)$ & $0.47(1.23)$ & $0.30(0.80)$ & $0.33(0.76)$ \\
\hline$\overline{\text { ED visits } \dagger}$ & $0.03(0.20)$ & $0.07(0.34)$ & $0.04(0.20)$ & $0.08(0.37)$ & $0.02(0.18)$ & $0.05(0.24)$ \\
\hline Hospital visits & $0.03(0.19)$ & $0.04(0.27)$ & $0.02(0.14)$ & $0.04(0.30)$ & $0.03(0.27)$ & $0.03(0.17)$ \\
\hline \multicolumn{7}{|c|}{$\overline{\text { Multivariate models } \ddagger}$} \\
\hline & Estimate & $P$ Value & Estimate & $P$ Value & Estimate & $P$ Value \\
\hline$\overline{\mathrm{SABA}}$ & 1.33 & $<0.001$ & 1.31 & $<0.001$ & 1.40 & 0.03 \\
\hline OCS & 1.04 & 0.76 & 1.26 & 0.18 & 0.71 & 0.20 \\
\hline ED/hospital visits & 0.58 & 0.04 & 0.80 & 0.47 & 0.25 & 0.02 \\
\hline \multicolumn{7}{|c|}{$\begin{array}{l}\text { * Significantly greater number of pharmacy claims for SABA in ICS/MON compared with ICS/SAL patients for each comparison: total population, } P<0.001 \text {; prion } \\
\text { ICS use, } P<0.001 \text {; no prior ICS use, } P=0.03 \text {. } \\
\text { † Significantly fewer ED/hospital visits for ICS/MON vs. ICS/SAL for the total population comparison, } P=0.04 \text {. } \\
\text { \#ICS/SAL served as the reference group for all models; relative risk was estimated using Poisson regression for model of SABA fills and odds ratio was estimated } \\
\text { using logistic regression for models of OCS fills and ED/hospital. } \\
\text { ED=emergency department; ICS=inhaled corticosteroid; MON= montelukast; OCS=oral corticosteroid; SABA=short-acting beta-agonist; SAL=salmeterol. }\end{array}$} \\
\hline
\end{tabular}

health status at that time. Based on emergent care and rescuemedication-use patterns in the preindex period, those adding a second controller sequentially to an ICS required additional intervention to better manage their asthma. The addition of MON or SAL to their ICS regimen decreased SABA, OCS, ED visits, and hospital admissions. In contrast, patients beginning ICS/MON or ICS/SAL on the same day did not experience improvements in SABA fills. Similarly, in a review of asthma combination therapy as first-line therapy, Ni Chroinin et al. ${ }^{22}$ concluded that the initiation of combination therapy does not significantly reduce SABA use as compared with ICS alone. It is possible that beginning asthma treatment with a single controller therapy and periodically reassessing patients' asthma control may allow providers to more accurately determine and respond to the needs of their patients.

Chronic LABA use presents a challenge in the measurement and interpretation of SABA use. The asthma treatment guidelines continue to emphasize minimal use of SABA as a goal of therapy, but it is unclear how SABA use should be interpreted in patients using a LABA daily compared with those who are not. A decreased need for a SABA in patients using a LABA daily may simply reflect the replacement of one bronchodilator for another. In clinical practice, it may be reasonable to establish acceptable levels of SABA use by medication regimen. It is unknown whether total beta-agonist consumption (a measure of SABA + LABA) is important or whether providers should simply continue to make distinctions between demand use and regular use of beta-agonists. Additional research is needed to more fully understand how chronic LABA use impacts the use of SABA, for both clinical management and research purposes.

The findings of this analysis are in agreement with long-term comparative trials reporting equivalent asthma control for patients treated with fluticasone plus MON or fluticasone plus SAL. Our study sought to strengthen this body of evidence by using the propensity score methodology to correct for baseline differences in groups, thereby examining the relative effectiveness of ICS/MON and ICS/SAL in comparable patient groups.

It should be noted that this study purposely predates the introduction of the fluticasone propionate/SAL fixed-dose combination product (Advair). This fixed-dose combination product is recommended for patients not adequately controlled on other asthma controller medications or whose disease severity clearly warrants initiation of treatment with 2 maintenance therapies. Fixed-dose combination products may offer an advantage for patients who need the simplicity and convenience of 2 therapies in 1 device and do not require tapering of the individual medications. The use of 2 separate medications, such as MON with ICSs, allows greater flexibility in dosing than fixed doses. The ability to taper ICS dosage when used concomitantly with MON has been demonstrated. ${ }^{23}$ Flexibility in dosing allows for convenient step-up in ICS dose, as recommended in the guidelines; this is more difficult with the fixed-dose combination typically used when SAL is chosen as the add-on therapy. The ability to make incremental changes in asthma medication reg- 


\section{Administrative Claims Analysis of Asthma-Related Health Care Utilization for Patients Who Received Inhaled Corticosteroids With Either Montelukast or Salmeterol as Combination Therapy}

imens allows both physicians and patients to titrate medications as needed to achieve asthma control.

\section{Limitations}

This analysis was performed using medical and pharmacy claims to examine resource utilization for asthma. Detailed information about the patients' asthma symptoms, lung function, or treatment preferences that might affect the combination therapy prescribed are generally not available in claims databases and could not be accounted for in this analysis. In addition, the presence of a pharmacy claim does not guarantee patient use of the medication or indicate how the physician instructed the patient to use the medication. Secondly, while the propensity score technique was used to identify comparable patient groups for comparison, this method accounts only for variables that have been observed or measured; for instance, we could not adjust for ethnicity since these data were not available.

In addition, we did not study financial measures associated with asthma-related resource utilization as an outcome since these data are difficult to interpret in claims. Cost data in claims are subject to wide variability in amounts charged and paid for any particular service, given contractual differences that can exist across employer-sponsored health plans and the lack of sufficient information to adjust for these differences.

\section{Conclusion}

In this matched cohort, use of ICS/MON compared with ICS/SAL resulted in similar odds of OCS fills, decreased odds of ED visits and asthma-related hospitalizations, but higher utilization of SABAs.

\section{ACKNOWLEDGMENTS}

The authors would like to acknowledge Phong Duong, PharmD, Merck \& Co., Inc, West Point, PA, for his contributions to the conception and design of analysis; David Anstatt, MBA, for his management, presentation, and interpretation of data (he was an employee of Merck at the time of this study); Data Virtuoso, Inc., Schwenksville, PA, for its programming assistance; and Judith Grief, Griffin Communications, East Brunswick, NJ, for writing assistance.

\section{DISCLOSURES}

Funding for this research was provided by Merck \& Co., Inc., which also provided scientific and technical input; it was obtained by authors Felicia C. Allen-Ramey, Leona E. Markson, and Shiva G. Sajjan, who are employed by Merck. Authors Don Bukstein and Allan Luskin disclose no potential bias or conflict of interest relating to this article.

Allen-Ramey served as principal author of the study. Study concept and design were contributed by Allen-Ramey, Sajjan, and Markson, with input from Bukstein and Luskin. Data collection was primarily the work of AllenRamey and Markson, with input from the coauthors; data interpretation was primarily the work Bukstein and Luskin, with input from the coauthors. Drafting of the manuscript and its revision were primarily the work of AllenRamey and Markson, with input from the coauthors.

\section{REFERENCES}

1. National Institutes of Health, National Heart, Lung, and Blood Institute. National Asthma Education and Prevention Program. Clinical practice guidelines, Expert Panel Report 2: guidelines for the diagnosis and management of asthma. Available at: www.nhlbi.nih.gov/guidelines/asthma/asthgdln.pdf. Accessed October 13, 2004.

2. National Asthma Education and Prevention Program. Expert Panel Report: guidelines for the diagnosis and management of asthma update on selected topics, 2002. J Allergy Clin Immunol. 2002;110(5 pt 2):S141-S219.

3. Dempsey OJ, Wilson AM, Sims EJ, Mistry C, Lipworth BJ. Additive bronchoprotective and bronchodilator effects with single doses of salmeterol and montelukast in asthmatic patients receiving inhaled corticosteroids. Chest. 2000;117:950-53

4. Fish, JE, Israel E, Murray JJ, et al. Salmeterol powder provides significantly better benefit than montelukast in asthmatic patients receiving concomitant inhaled corticosteroid therapy. Chest. 2001;120:423-30.

5. Nelson HS, Busse WW, Kerwin E, et al. Fluticasone propionate/salmeterol combination provides more effective asthma control than low-dose inhaled corticosteroid plus montelukast. J Allergy Clin Immunol. 2000;106:1088-95.

6. Ringdal N, Eliraz A, Pruzinec R, et al. The salmeterol/fluticasone combination is more effective than fluticasone plus oral montelukast in asthma. Respir Med. 2003;97:234-41.

7. Wilson AM, Dempsey OJ, Sims EJ, Lipworth BJ. Evaluation of salmeterol or montelukast as second-line therapy for asthma not controlled with inhaled corticosteroids. Chest. 2001;119:1021-26.

8. Bjermer L, Bisgaard H, Bousquet J, et al. Montelukast and fluticasone compared with salmeterol and fluticasone in protecting against asthma exacerbations in adults: one year, double blind, randomised, comparative trial. BMJ. 2003;327:891-96.

9. Ilowite J, Webb R, Friedman B, et al. Addition of montelukast or salmeterol to fluticasone for protection against asthma attacks: a randomized, doubleblind, multicenter study. Ann Allergy Asthma Immunol. 2004;92:641-48.

10. Wang SW, Liu X, Wiener DJ, Sennett C, Bowers BW, Legorreta AP. Comparison of prevalence, cost, and outcomes of a combination of salmeterol and fluticasone therapy to common asthma treatments. Am J Manag Care. 2001;7:913-22.

11. Stempel DA, O’Donnell JC, Meyer JW. Inhaled corticosteroids plus salmeterol or montelukast: effects on resource utilization and costs. J Allergy Clin Immunol. 2002;109:433-39.

12. O'Connor RD, O'Donnell JC, Pinto LA, Weiner DJ, Legorreta AP. Two-year retrospective economic evaluation of three dual-controller therapies used in the treatment of asthma. Chest. 2002;121:1028-35.

13. Bukstein D, Henk H, Luskin A. Effect of adding leukotriene modifier or salmeterol to inhaled corticosteroids on outcomes: confounding factor in assessing effectiveness [abstract]. J Allergy Clin Immunol. 2003;111(2)(suppl): S109.

14. Donahue JG, Weiss ST, Livingston JM, Goetsch MA, Greineder DK, Platt R. Inhaled steroids and the risk of hospitalization for asthma. JAMA. 1997;277 (11):887-91.

15. Schatz M, Nakahiro R, Crawford W, Mendoza G, Mosen D, Stibolt TB. Asthma quality-of-care markers using administrative data. Chest. 2005;128 (4):1968-73

16. Schatz M, Nakahiro R, Jones CH, Roth RM, Joshua A, Pettiti D. Asthma population management: development and validation of a practical 3-level risk stratification scheme. Am J Manag Care. 2004;10:25-32.

17. Rosenbaum P, Rubin D. The central role of the propensity score in observational studies for causal effects. Biometrica. 1983;70:41-55.

18. Parsons LS. Reducing bias in a propensity score matched-pair sample using greedy matching techniques. Proceedings of the 26th annual SAS users group international conference; Cary, NC: SAS Institute, Inc.; 2001. 


\section{Administrative Claims Analysis of Asthma-Related Health Care Utilization for Patients Who Received Inhaled Corticosteroids With Either Montelukast or Salmeterol as Combination Therapy}

19. Efron B, Tibshirani RJ. An Introduction to the Bootstrap. San Francisco: Chapman \& Hall; 1993.

20. Bukstein DA, Henk HJ, Luskin AT. A comparison of asthma-related expenditures for patients started on montelukast versus fluticasone propionate as monotherapy. Clin Ther. 2001;23:1589-1600.

21. Bukstein DA, Luskin AT, Bernstein A. "Real-world" effectiveness of daily controller medicine in children with mild persistent asthma. Ann Allergy Asthma Immunol. 2003;90:543-49.
22. Ni Chroinin M, Greenstone IR, Ducharme FM. Addition of inhaled long-

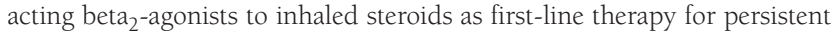
asthma in steroid-naive adults. Cochrane Database Syst Rev. 2004(4). Art. no.: CD005307. DOI:10.1002/14651858.CD005307.

23. Lofdahl CG, Reiss TF, Leff JA, et al. Randomised, placebo-controlled trial of effect of a leukotriene receptor antagonist, montelukast, on tapering inhaled corticosteroids in asthmatic patients. BMJ. 1999;319:87-90. 